\title{
CORRELATIONS AMONG PERCEPTIVE AND ASSOCIATIVE PROCESSES.
}

BY PROFESSOR H. A. AIKENS, AND PROFESSOR E. L. THORNDIKE,
Western Reserve Unzversity, WITH THE ASSISTANCE OF MISS ELIZABETH HUBBELI, Westem Reserve University.

It has been the habit of psychologists to use the words 'memory,' 'attention,' ' delicacy of discrimination,' etc., as if they referred to general mental functions, and the words 'quickness' and 'accuracy' and 'ability,' as if they referred to general mental qualities. But any consideration of the nervous basis of mental life or of the patent facts of human nature suggests that $\dot{a}$ priori it is more rational to look on the mind as a multitude of particular capacities, particular associations and particular acts, all of which may be highly independent of each other. And the studies of Thorndike and Woodworth ${ }^{1}$ on the effect of training, of Wissler ${ }^{2}$ on the correlation of mental tests and of Norsworthy ${ }^{3}$ on the correlation of school abilities, give actual evidence that such is the fact.

The extent to which any one mental trait presupposes any other is in fact in every case a matter to be actually measured. We cannot tell beforehand what the relationships are. The present study gives measurements of such relationships in the case of a number of functions, all of which depend upon quickness and accuracy in associating certain thoughts or acts with certain percepts either directly or indirectly through other ideas which the percepts call up. The associations were in every case such as involved (in the subjects tested) attentive selection of correct and purposive inhibition of incorrect ideas. They were controlled associations. The functions in question were much more alike than were those examined by Wissler. We

'Psychological Review, Vol. VIII., Nos. 3, 4 and 6 (Igor).

Psychological, Review, Monograph Supplement No. 16 (IgOr).

'Journal of Pedagogy', Vol. XIV., No. I (IgOI). 
have examined the relationships between functions in an extremely favorable case.

The results reinforce the evidence showing that functions apparently closely similar may really be to a large extent independent specializations. For instance the ability to call up quickly the opposites of 'good,' 'rich,' 'heavy,' etc., is by no means identical with the ability to call up quickly the letters coming before $\mathrm{c}, \mathrm{k}, \mathrm{t}$, etc., or with the ability to call up quickly the answers to $7+4$, II $+9,20+6$, etc. 'Quickness of association' as an ability determining the speed of all one's associations is a myth. Quickness in noticing words containing the two letters $r$ and $e$ does not to any appreciable extent involve quickness in noticing words grossly misspelled, nor does accuracy in the one involve anything like equal accuracy in the other. The 'attention' and 'discrimination' required in the two cases must therefore be different things.

Our results also suggest the possibility of clearly defining the classes of functions which we may expect to find closely related. For in the tests involving quickness and accuracy in purpesive associations there is much closer clependence than in the tests involving quickness and accuracy of perception, though to the speculative psycholorist the latter would seem to be cases of the same function.

It may be added that both of these conclusions are supported by the results of many other correlations not yet worked out in detail and so not presented here.

The importance to general psychological theory of measures of the relationship of different mental functions is obvious. Where introspective analysis fails to discover the exact structure of a mental process, the study of its relationships with other better known functions may succeed. Moreover the whole question of the influences of heredity, maturity and training will be illuminated by a knowledge of the necessary bonds and interactions of the different mental processes.

The tests were all given by one person; they were given to 60 boys and girls in the eighth grade (the highest) and to 80 in the fifth grade. Care was taken that in all the tests all the pupils 
had the same conditions of explanation, incentive, time, etc. The tests were the following:

I. To mark every mispelled word in this passage (time, I 20 seconds):

I percicved, about four years ago, a large spiider in one korner of my room, makeng ins web; and through the maid frequentely leveled her fatale brom against the lobors of the little anemal, I had the good fortoone then to prevente its distrucsion, and, I may say, it mor than paid me by the intertainement it aforded.

In thre days the wecb was, with encredable diligence, compleeted; nor could $I$ avod thinkeing that the insect seemed to exult in its new abode. It ofen treversd it round, and exsamined the strenth of every part of it, retierd into its whole, and came out very ferquently. The first inemy, bowever, it bad to inconter was another and much larger spidur, which, having no web of its owne, and haveing probibly hexausted all its stock in former labors of this kind, came to invaide the prouperty of its nieghbore.

Soon a terreble encounter ensooed, in which the invader seemed to have the victorie, and the laborius spider was oblecged to take refug in its bole. Upon this I perceived the victer useing every art to draw the enemey from his strongbolde. He seemed to go of, but quicklie returned, and, when he found all arts vane, began to dimoilish the new web withoute mercy. This broght on another battle, and contary to my expextations, the laborious spider became conckeror, and fairly killed his antagonist.

Nou in pieccable possession of what was justely its own, it awated three days with the uttmoste impatients, repairiug the breeches of its web, and taking no sustevance that I could perceive. Ate last, houever, a large blue fly fell into the snaire, and strugled hard to get lose The spider gave it leeve to intangle itself as much as possible, but it seemed to be to strong for the cobwebe.

I must own I was grately serprised when I saw the spider imediately sally out, and in lese than a minite wheave a new nett around its capthive, by wich the moshun of its wings was stoped, and, when it was fairely hampered in this naver, it was siezed and druged into the houle.

In this manner it lifed, in a precarious staite, and Natcher seemed to have fited it for such a life, for upon a singl fly it subsested for a weak. I put a waspe anto the neat, but the spider sit it free.

2. To mark every word containing $r$ and $e$ in this passage (time, 60 seconds):

Then the carelessly dressed gentlemen stepped lightly into Warren's carriage and held out a small card. John vanished behind the bushes and the carriage moved along down the driveway. The audience of passers-by which had been gathering about them melted away in an instant learing only a poor old lady on the curb. Albert was sadly striding across the field stopping now and then to look back at the village or staring at the bit of paper which he still held tightly grasped in his left hand. He wished to keep his appointment; nevertheless he felt that he ought to go back to Cromley to ascertain in what durection the stranger might be going. The highway lay on bis left seeming 
for all the world like a dusty ribbon. Before him gleamed the spire of Relton church. His thoughts flew to his former roving in the days when Clayton and he were working for Fleckmer. "What an insatiable greed for power that man had," he thought, "I on the contrary have really no ambition." He laughed bitterly. "Hopelessly inactive I truly am." A partridge flew up ahead of him. He tried to hit it, but merely knocked off some leaves.

3,4 and 5 . To fill out the blanks $A, B$ and $C$, thirty seconds being given for $A$ and also for $B$ and fifteen seconds for $C$.

A.

Write as fast as you can beside each of the words in the column a word that means the opposite' thing from it.

stupid
hard-working
strong
sane
obnoxious
foolish
handsome
adroit
superior
loquacious
rapid
generous
straight
separate
up
always
joy
high
obscure
proud

B.

Write as fast as you can beside each of the words in the column a word that means the opposite thing from it.
C. Write as quickly as you can beside each letter in the column, the letter that comes before it in the alphabet.

6. To do the following examples ( $\mathrm{I} 20$ seconds):

$\begin{array}{ll}\text { good } & f \\ \text { outside } & \mathrm{k} \\ \text { friend } & \mathrm{s} \\ \text { quick } & \mathrm{p} \\ \text { tall } & \mathrm{w} \\ \text { big } & \mathrm{l} \\ \text { loud } & \mathrm{e} \\ \text { white } & \mathrm{r} \\ \text { light } & \mathrm{d} \\ \text { happy } & \mathrm{o} \\ \text { false } & \mathbf{v} \\ \text { like } & \mathrm{j} \\ \text { rich } & \text { n } \\ \text { sick } & \mathbf{t} \\ \text { glad } & \mathrm{h} \\ \text { thin } & \\ \text { empty } & \\ \text { war } & \\ \text { many } & \\ \text { above } & \end{array}$

ADDITION EXAMPLES.

\begin{tabular}{lllll}
17 & 26 & 27 & 72 & 23 \\
42 & 51 & 24 & 14 & 47 \\
38 & 47 & 83 & 39 & 86 \\
91 & 82 & 19 & 81 & 54 \\
54 & 63 & 45 & 26 & 36 \\
\hline 17 & 42 & 38 & 91 & 36 \\
26 & 51 & 47 & 82 & 26 \\
27 & 24 & 83 & 19 & 45 \\
72 & 14 & 39 & 62 & 63 \\
23 & 47 & 86 & 54 & 54 \\
\hline
\end{tabular}




\begin{tabular}{lllll}
41 & 53 & 67 & 78 & 86 \\
52 & 67 & 86 & 37 & 32 \\
86 & 34 & 23 & 96 & 44 \\
23 & 78 & 45 & 72 & 36 \\
35 & 19 & 67 & 23 & 68 \\
\hline & & & & \\
45 & 52 & 19 & 45 & 23 \\
13 & 86 & 78 & 67 & 72 \\
68 & 23 & 67 & 78 & 36 \\
77 & 35 & 23 & 37 & 68 \\
86 & 67 & 86 & 96 & 39 \\
\hline
\end{tabular}

In the misspelled word test each individual was given five scores: (1) The number of lines covered; (2) the number of words marked that should have been marked; (3) the number of words marked per line; (4) the number of words marked that should not have been marked; (5) a mark for his general efficiency in the test, obtained by finding in 2 and 3 his distance above or below the average for his grade in terms of the average deviation of the grade from that average, adding the two distances together, and adding or subtracting a small amount to the figure thus obtained in the case of those who were much above or below the average in the number of words incorrectly marked. Similar scores were given in the case of the $R-E$ test.

In the hard opposites (A), easy opposites (B), and alphabet tests $(C)$, each individual was given five scores, namely, (I) the point reached in the test, (2) the number done, (3) the number of errors, (4) the percentage of errors to the number done, and (5) a general score for efficiency calculated differently in the three cases. The method of calculation with the hard opposites was to subtract twice the number of errors from the number done, multiply the product by two and subtract the number of omissions; with the easy opposites do the same, save that three times the number of omissions were subtracted; with the alphabet test twice the number of errors were subtracted from the number done, and a correction made in the few cases where there were omissions according to the nature of each case. These scores of efficiency are to some extent arbitrary and are 
possibly unfair. They are not of much importance in the discussion.

Each individual was also given a score for the total number done in all three of these tests, a score for the total number of errors, a score for the ratio of total errors to total number done, a score for the total number correct, and a score for total efficiency obtained by adding the efficiency scores in hard opposites and alphabet to one-half the score in easy opposites.

The scores given in the addition test were (I) number done, (2) number of errors, (3) number of errors per example, and (4) a score for general efficiency obtained by subtracting one-half of (2) from (I).

We have thus for each individual a record like this :

\section{Grace Alexander.}

Misspellad Words.

Number of lines

Number of correct words

Words per line

Incorrect words

2

Efficiency

RE

Number of lines

Number of correct words

Words per line

9

II

Incorrect words

1.2

Efficiency

$\mathrm{o}$

$-.68$

Number reached

Number done

Number of errors

Percentage of errors

Efficiency

$\begin{array}{ccc}\text { Hard opp } & \text { Easy opp } & \text { Alphabet } \\ 9 & 6 & 3 \\ 7 & 6 & 3 \\ \text { I } & 1 & 0 \\ \text { I4 } & 17 & 0 \\ \text { S } & 8 & 3\end{array}$

ashcciative trsts Conaried.

Total number done

Total number of errors 


$\begin{array}{lc}\text { Number done } & \\ \text { Number of errors } & 9 \\ \text { Percentage of errors } & 2 \\ \text { Efficiency } & \mathbf{. 2 2}\end{array}$

The relationship in the case of the individuals tested between the two abilities measured by any two of these tests will be represented by any figure or diagram or statement that shows how far variations in one of the abilities go with similar or opposite variations in the other. We shall use a single figure for that purpose. Its meaning will be clear from the following derivation in one case :

The relationship between the amount done in addition and

the total amount done in the three other association tests.

I5 students doing the least in addition, namely from 3 to 6 , got the following scores in the three other tests: 2 got I0, 3 got I2, I got I3, 3 got I4, I got I6, 3 got I7, I got I9, I got 20 . They averaged 14.5 . If these fifteen who did the least in addition had been the fifteen doing the least in the association tests they would have obtained the following scores: one 6 , one 7 , two 9 , six IO, four II and one I2, and would have averaged 9.9. The general average in the total for the three association tests was I7.6. The lowest 15 in addition were thus 3.I below the average in the total for the three association tests. If correlation had been perfect, $i$. e., if an individual's rank in one exactly corresponded with his rank in the other, they would have been 7.7 below. The degree of correlation for them was thus $4^{\circ}$ per cent.

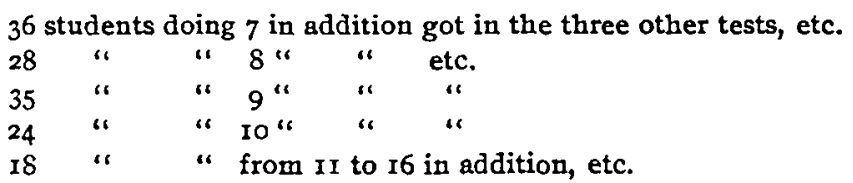

Data for all these groups similar to those given above for the lowest 15 are presented in Table A. 


\section{TABLE A.}

\section{RELATION BETWEEN AMOUNT DONE IN ADDITION AND AMOUNT DONE IN THE THREE COMBINED ASSOCIATION TESTS.}

Each figure in the table records that that many individuals did in addition the amount under which the figure stands and in the three combined association tests the amount opposite which the Ggure stands.

Number of cases.

Average amount in association tests.

Average if perfect correlation.

Actual deviations from general average.

Deviations of perfect correlation.

Percentages of correlation.

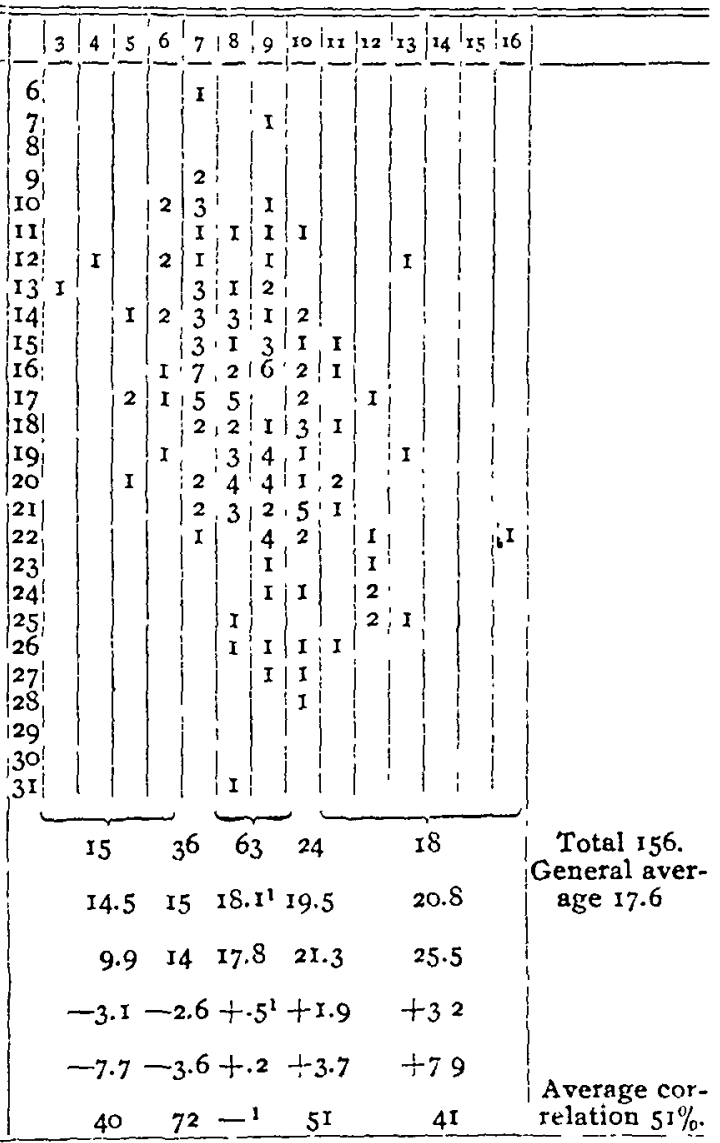

1 These cases so near the average should be omitted in computing the general relationship, since they give a different result if grouped differently.

The average of the percentages of correlation for the different groups, gives a sufficiently though not the most accurate single figure to express the closeness of relationship between the two functions. Perfect correlation would be represented, of course, by $100 \%$, utter independence by $\%$, and antagonism in the two functions by a figure with a negative sign. 
The following relationship was worked out by the method just described. When there are two figures for the relationship the upper one refers to the relationship found in the 8th grade pupils, the lower one to that found in the $5^{\text {th }}$ grade pupils. Where only one figure is given, it refers to the 8th grade pupils alone.

Misspelled words marked (2) and R E. words marked (2). Quickness (and to some extent accuracy) of Perception................

Misspelled words per line (3) and R. E. words per line (3). Accuracy

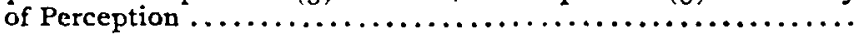

Misspelled words (efficiency (5)) and R. E. words (effeiency (5)) ... None or

Hard opposites (number done (2)) and easy opposites (number done

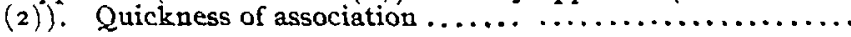

Hard opposites (number done) and alphabet (number done). Quick-

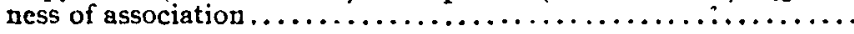

Alphabet (number done) and easy opposites (number done). Quickness of association . . . . . . . . . . . . . . . . . . . . . . . . . .

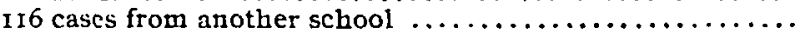

Per Cent of Correlation.

opposites (percentage of errors) and easy opposites (percent-

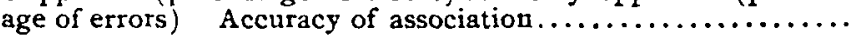

Hard opposites (percentage of errors) and alphabet (percentage of

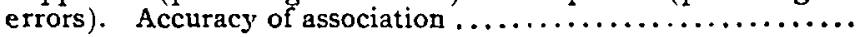

Alphabet (percentage of errors) and easy opposites (percentage of

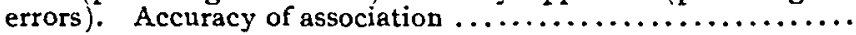

Hard opposites (efficiency) and easy opposites (efficiency).........

Hard opposites (efficiency) and alphabet (efficiency) .......... 34

Alphabet (efficiency) and easy opposites (efficiency) .......... 60

Association tests (total number done) and addition (number done).. $\left\{\begin{array}{l}50 \\ 20\end{array}\right.$

Association tests (total percentage of errors) with addition (percen- None or tage of errors ) $\ldots \ldots \ldots \ldots \ldots \ldots \ldots \ldots \ldots, \ldots \ldots \ldots \ldots$, slight.

Association tests (efficiency) and addition (efficiency).......... $4^{8}$

Association tests (total number done) and R. E. (number of words None or

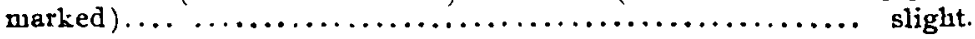

Association tests (total number done) and R. E. (lines marked)....8 or less.

Association tests (total number done) and misspelled words marked 20

Association tests (efficiency) and R. E. (efficiency) ............ None or slight.

Association tests (efficiency) and misspelled words (efficiency) .... 50 Addition (number done) and R. E. (number of words marked) ..... None or slight.

Addition (number done) and misspelled words marked........... 20

Addition (efficiency) and R. E. (efficiency) ................. None or slight.

Addition (efficieucy) and misspelled words (efficiency).......... 50 